\title{
Uncertainty budget for determinations of mean isomer shift from Mössbauer spectra
}

Fock, Jeppe; Bogart, L.K.; Posth, O.; Hansen, Mikkel Fougt; Pankhurst, Q.A.; Frandsen, Cathrine

Publication date:

2015

Document Version

Publisher's PDF, also known as Version of record

Link back to DTU Orbit

Citation (APA):

Fock, J., Bogart, L. K., Posth, O., Hansen, M. F., Pankhurst, Q. A., \& Frandsen, C. (2015). Uncertainty budget for determinations of mean isomer shift from Mössbauer spectra. Poster session presented at The International Conference on the Applications of the Mössbauer Effect, Hamburg, Germany.

\section{General rights}

Copyright and moral rights for the publications made accessible in the public portal are retained by the authors and/or other copyright owners and it is a condition of accessing publications that users recognise and abide by the legal requirements associated with these rights.

- Users may download and print one copy of any publication from the public portal for the purpose of private study or research.

- You may not further distribute the material or use it for any profit-making activity or commercial gain

- You may freely distribute the URL identifying the publication in the public portal 


\section{Uncertainty budget for determinations of mean isomer shift from Mössbauer spectra}

\section{Jeppe Fock, ${ }^{1,4, *}$ Lara Katrina Bogart, ${ }^{2}$ Oliver Posth, ${ }^{3}$ Mikkel Fougt Hansen, ${ }^{1}$}

\section{Quentin A. Pankhurst, ${ }^{2}$ and Cathrine Frandsen 4}

${ }^{1}$ Department of Micro- and Nanotechnology, DTU Nanotech, Building 345 East, Technical University of Denmark, DK-2800 Kongens Lyngby, Denmark

2 UCL Healthcare Biomagnetics Laboratory, University College London, 21 Albemarle Street, London W1S 4BS, U.K

${ }^{3}$ Department 8.21 Biomagnetism, Physikalisch-Technische Bundesanstalt, Abbestr. 2-12, 10587 Berlin, Germany

${ }^{4}$ Department of Physics, DTU Physics, Building 307, Technical University of Denmark, DK-2800 Kongens Lyngby, Denmark

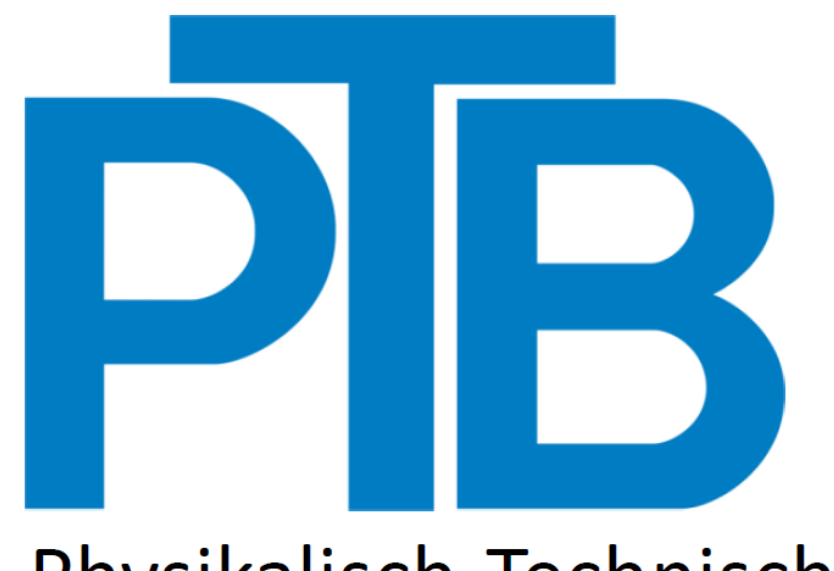

*Corresponding author: JepF@nanotech.dtu.dk Bundesanstalt

\section{Introduction and Motivation}

Mössbauer spectroscopy is one of the few methods

which is able to distinguish between magnetite

$\left(\mathrm{Fe}_{3} \mathrm{O}_{4}\right)$ and maghemite $\left(\mathrm{Fe}_{2} \mathrm{O}_{3}\right)$, eg.

1. The presence or absence of characteristic lines

2. Area ratio of spectral components

3. Mean isomer shift $\left(\bar{\delta}=\sum_{n}^{N} A_{n} \delta_{n} / A\right)$

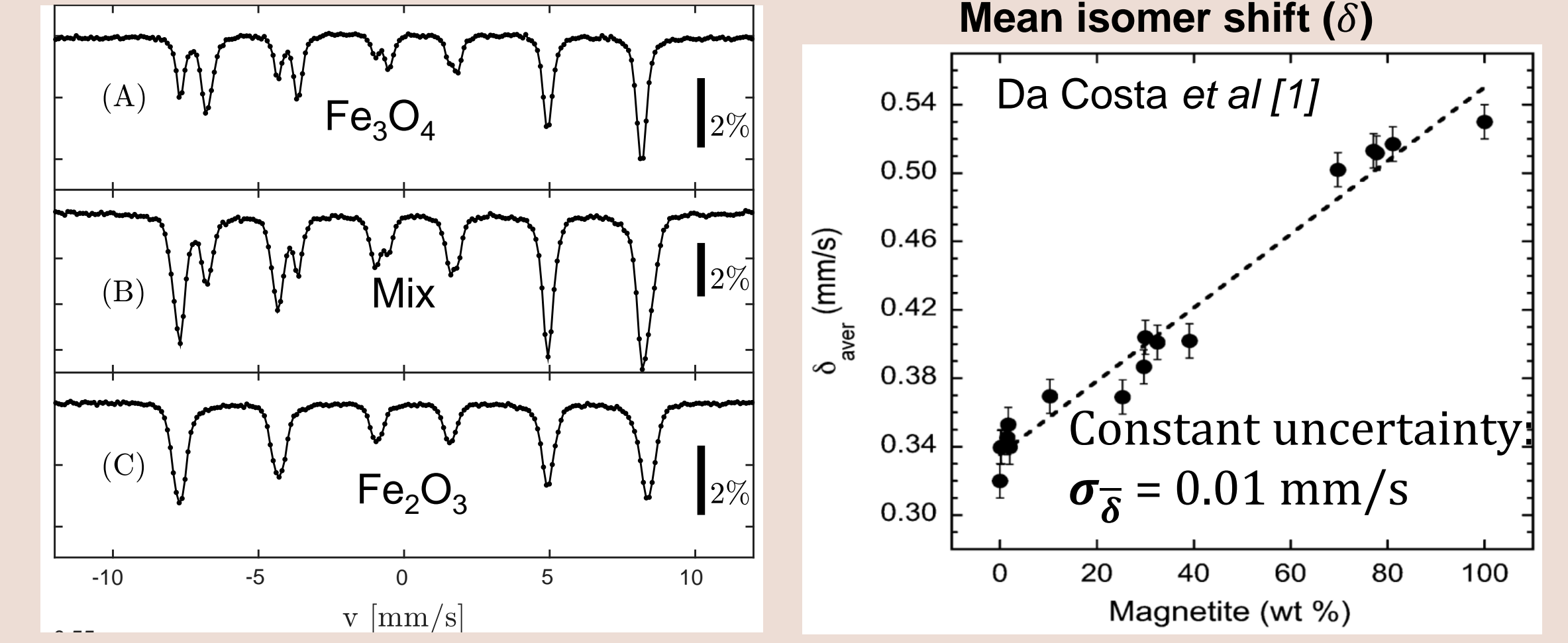

The uncertainty of the mean isomer shift $\left(\boldsymbol{\sigma}_{\bar{\delta}}\right)$ can be

divided up into four uncorrelated contributions:

1) The calibration $\left(\sigma_{c a l}\right)$,

2) Correction of Second order Doppler shift $\left(\sigma_{\Delta \delta}\right)$

3) The fitting of the spectrum ( $\left.\sigma_{f i t}\right)$,

4) Experimental errors $\left(\sigma_{\mathrm{err}}\right)$.

\section{Calibration, $\sigma_{\text {cal }}$}

Channel-velocity calibration is performed by fitting

$$
c_{n}=\frac{E_{n}}{k}+c_{0} \text { for } 1 \leq n \leq 6
$$

From the linear regression the covariance matrix is

$c_{n}=\frac{-E_{13-n}}{k}+c_{0}+\frac{c_{f}}{2} \quad$ for $7 \leq n \leq 12$

to all twelve peaks in the unfolded $\alpha$-Fe foi

reference spectrum (fig 1a) using the energy of $n$th

line in the reference spectrum $\left(E_{n}\right)$

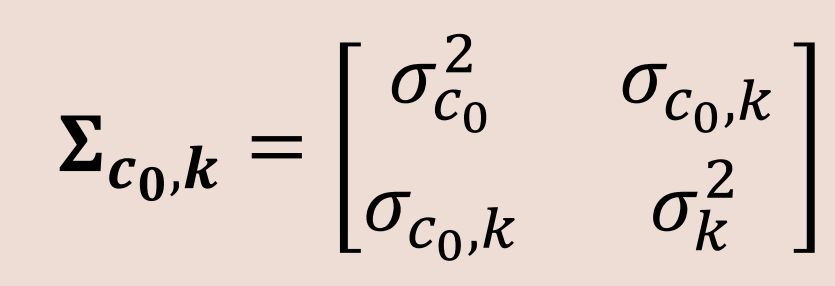

Uncertainty in the isomer shift is

$\sigma_{c a l}=\sqrt{\frac{\delta^{2}}{k^{2}} \cdot \sigma_{k}^{2}+k^{2} \cdot \sigma_{c_{0}}^{2}-2 k \bar{\delta} \sigma_{k, c_{0}}}$

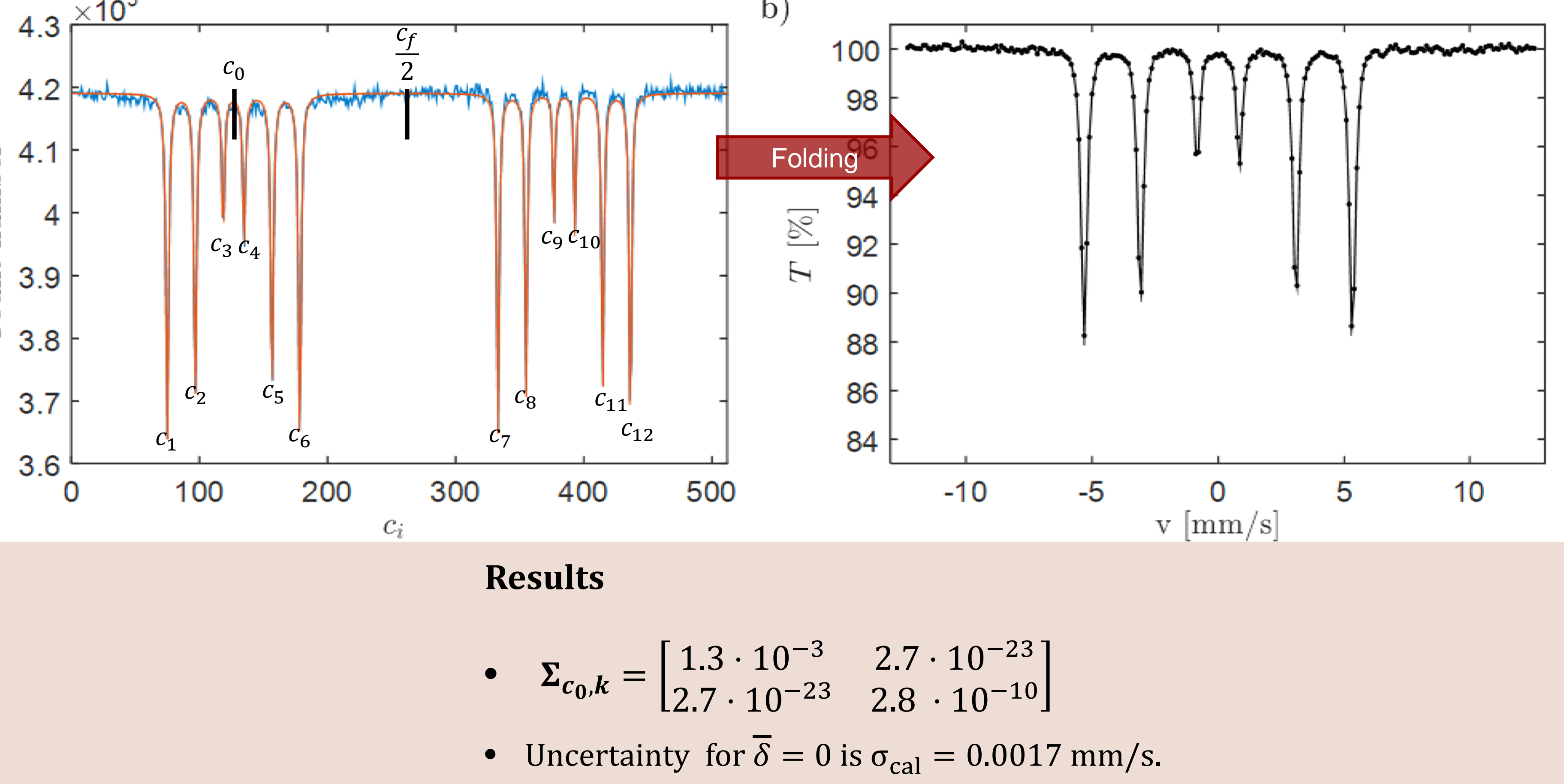

\section{Fitting of spectrum, $\sigma_{\mathrm{fit}}$}

1. Spectrum $S_{i}$ fitted to model $f\left(v_{i}, \boldsymbol{p}\right)$ by minimizing:

$\chi^{2}=\sum_{i}\left(f_{i}(\boldsymbol{p})\right)^{2}$ where $f_{i}(\boldsymbol{p})=\frac{S_{i}-f\left(v_{i} \boldsymbol{p}\right)}{\sigma_{S_{i}}}$

Fitted parameters $(\boldsymbol{p})$ consist of the areas $\left(\boldsymbol{A}_{n}\right)$ and isomer shifts $\left(\delta_{n}\right)$ of the $N$ spectral components.

2. The covariance matrix of fitting parameters

$\boldsymbol{\Sigma}_{\mathbf{p}}=\left(\boldsymbol{J}\left(\boldsymbol{p}^{*}\right)^{T} \boldsymbol{J}\left(\boldsymbol{p}^{*}\right)\right)^{-1}, \quad \boldsymbol{J}(\boldsymbol{p})=\left[\begin{array}{ccc}\frac{\partial f_{1}(\boldsymbol{p})}{\partial A_{1}} & \ldots & \frac{\partial f_{1}(\boldsymbol{p})}{\partial \delta_{N}} \\ \vdots & \ddots & \vdots \\ \frac{\partial f_{n}(\boldsymbol{p})}{\partial A_{1}} & \ldots & \frac{\partial f_{n}(\boldsymbol{p})}{\partial \delta_{N}}\end{array}\right]$

3. Uncertainty of mean isomer shift is calculated by propagation of uncertainties:

$$
\begin{gathered}
\sigma_{\text {fit }}^{2}=\boldsymbol{J}_{\bar{\delta}} \boldsymbol{\Sigma}_{\mathbf{j}} \boldsymbol{J}_{\bar{\delta}}^{\mathbf{T}} \\
\boldsymbol{J}_{\bar{\delta}}=\left[\begin{array}{lllll}
\frac{\partial \bar{\delta}}{\partial A_{1}} \ldots \frac{\partial \bar{\delta}}{\partial A_{N}} & \frac{\partial \bar{\delta}}{\partial c_{1}} & \ldots & \frac{\partial \bar{\delta}}{\partial c_{N}}
\end{array}\right] \\
=\left[\begin{array}{lllll}
\frac{\delta_{i}-\bar{\delta}}{A} & \ldots & \frac{\delta_{N}-\bar{\delta}}{A} & \frac{A_{1}}{A} & \ldots
\end{array}\right]
\end{gathered}
$$

Results

a) Uncertainty of individual components is larger than $0.006 \mathrm{~mm} / \mathrm{s}$. Inducing correlations between parameters the uncertainty on $\bar{\delta}$ is $0.002 \mathrm{~mm} / \mathrm{s}$. b-c) Broadening of spectra increase uncertainty. d) Collapse into the doublet decreases uncertainty.
Multi-core, polystyrene iron oxide nanoparticles.

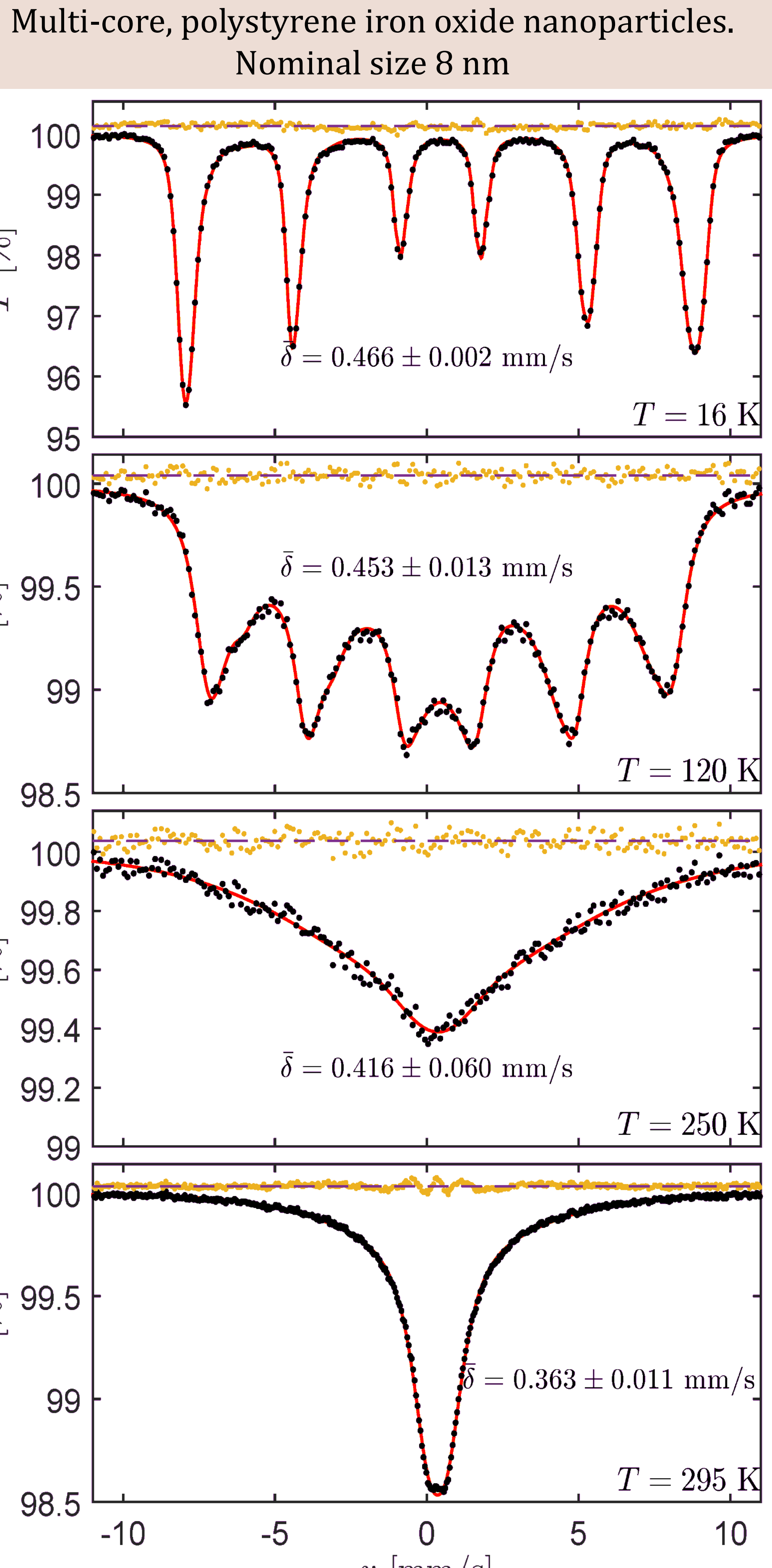

\section{Correction for SODS}

When the sample is measured at temperature $\left(T_{\mathrm{m}}\right)$ different from the temperature of reference compounds $\left(T_{\mathrm{r}}\right)$, the second order Doppler shift (SODS) describe the correction needed $(\Delta \delta)$ :

$\Delta \delta=\frac{-9 k_{B}}{2 m c}\left[T_{\mathrm{r}}\left(\frac{T_{\mathrm{r}}}{T_{\mathrm{D}}}\right)^{3} \int_{0}^{T_{\mathrm{D}} / T_{\mathrm{r}}} \frac{x^{3}}{e^{x}-1} \mathrm{~d} x-T_{\mathrm{m}}\left(\frac{T_{\mathrm{m}}}{T_{\mathrm{D}}}\right)^{3} \int_{0}^{T_{\mathrm{D}} / T_{\mathrm{m}}} \frac{x^{3}}{e^{x}-1} \mathrm{~d} x\right]$

The uncertainty is calculated using propagation of uncertainty:

$\sigma_{\Delta \delta}=\left|\frac{\partial \Delta \delta}{\partial T_{\mathrm{D}}}\right| \sigma_{T_{\mathrm{D}}}=\left|3 \frac{\Delta \delta}{T_{\mathrm{D}}}+\frac{9 k_{B}}{2 m c}\left(\frac{1}{e^{T_{\mathrm{D}} / T_{\mathrm{r}}-1}}-\frac{1}{e^{T_{\mathrm{D}} / T_{\mathrm{m}}-1}}\right)\right| \sigma_{T_{D}}$
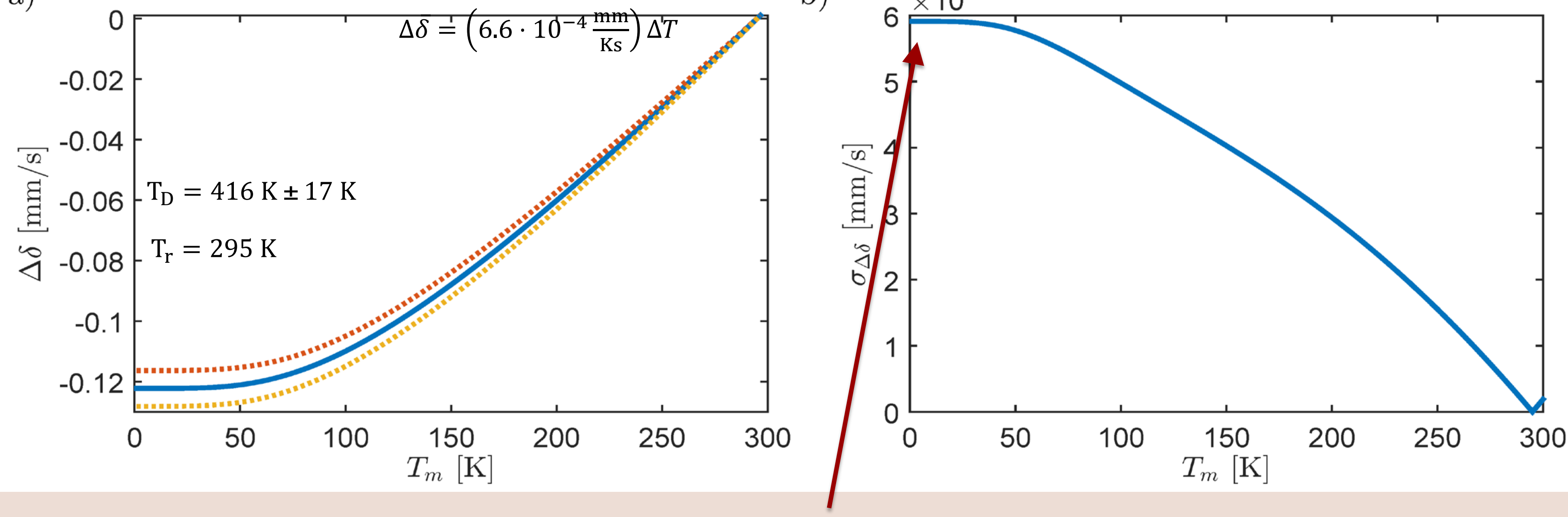

- The SODS correction adds an uncertainty of up to $0.006 \mathrm{~mm} / \mathrm{s}$ to the total uncertainty of $\bar{\delta}$.

- At high temperatures the mean isomer correction is approximately linear

- Uncertainty in the temperature $\left(\sigma_{\mathrm{T}}\right)$

- Seasonal or day/night temperature changes can induce uncertainties in $\bar{\delta}$

\section{Discussion and Conclusion}

The experimental error $\left(\sigma_{\text {err }}\right)$ is difficult to quantify.

- It is important to have:

- A flat non-sloping background

Sufficient counting statistics.

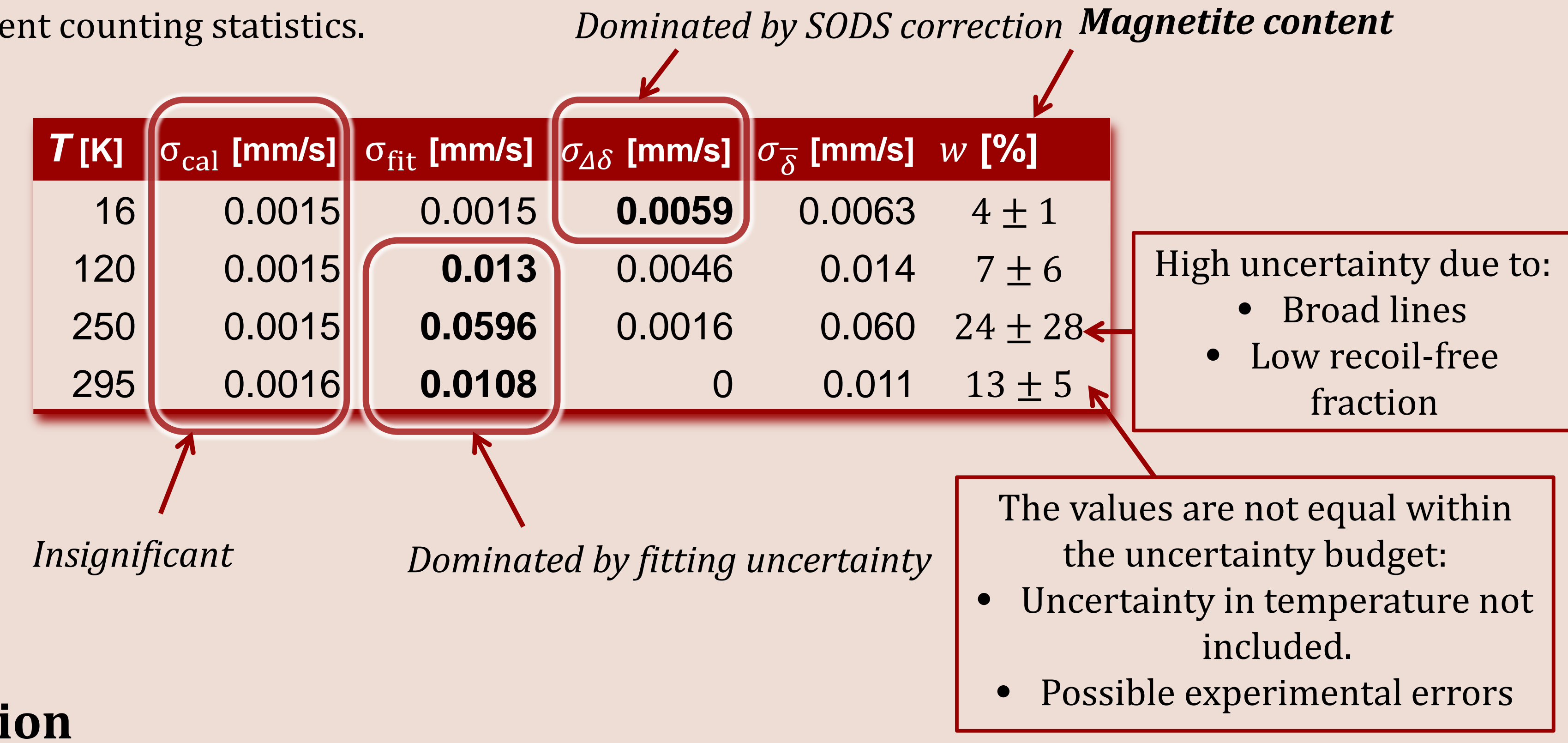

Conclusion

- The uncertainty is not constant

- The fit introduce uncertainties

o Spectrum with narrow lines gives low uncertainty

- Uncertainty in calibration is insignificant

- Correcting using SODS can result in a significant uncertainty

- Temperature uncertainty introduces uncertainty in mean isomer shift

\section{Acknowledgements}

We thank Abhilash Sugunan, Jens Sommertune and Andrea Fornara at the SP Technical Research Institute of Sweden for providing the nanoparticle sample. This work is financially supported by the EU FP7 Grant No. 604448-NanoMag.

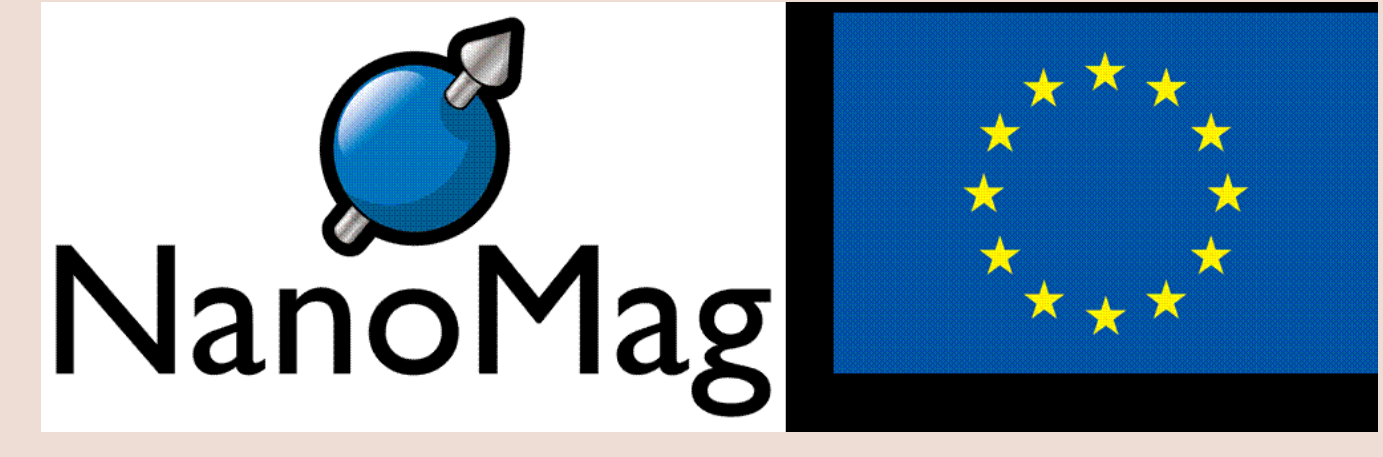

